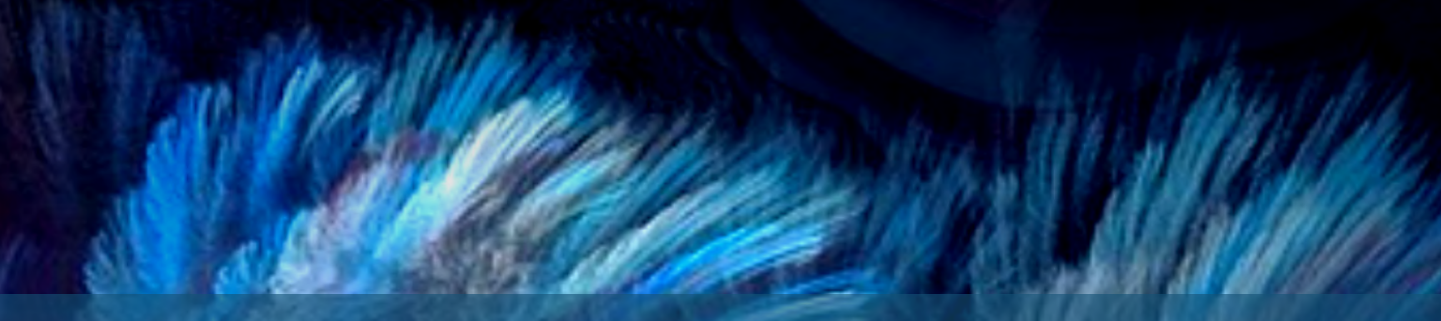

\author{
Lima, Perú - 2020
}

\section{PSEUDOCIENCIAS: UNA MANIFESTACIÓN DEL PENSAMIENTO ERRADO}

por
Freddy Jaimes

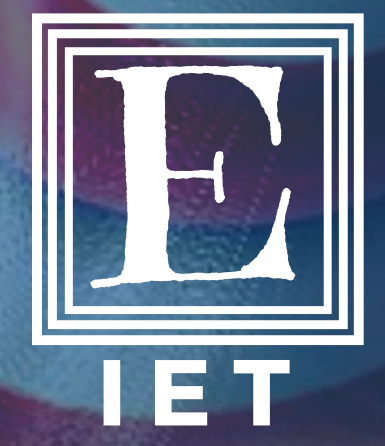

Instituto de Extrapolítica y Transhumanismo 


\title{
PSEUDOCIENCIAS: UNA MANIFESTACIÓN DEL PENSAMIENTO ERRADO
}

\author{
por \\ Freddy Jaimes Álvarez
}

\begin{abstract}
Resumen: La pseudociencia suele ser identificada como una manifestación de la ignorancia científica o una inexactitud en conceptos científicos que proviene de una confusión (confundir el concepto de satélite con el de planeta, o el concepto de la energía en física con el concepto tradicional ajeno a esta ciencia); sin embargo, la pseudociencia no se limita a una información errada, sino que implica una forma de pensar el mundo y las relaciones propias con ese mundo. Este artículo se escribe desde la preocupación de intentar entender la pseudociencia como un fenómeno del pensamiento y la posibilidad de acceder a su comprensión.
\end{abstract}

Palabras clave: Pensamiento, pseudociencias, filosofía, psicología, lógica, falacias.

Sobre el autor. Licenciado en psicología por la Universidad San Martín de Porres. Magister en Investigación y Docencia Universitaria y Doctor en Psicología por la Universidad Inca Garcilaso de la Vega. Miembro de la Sociedad Secular Humanista del Perú.

Información de contacto: fjal2002@gmail.com

Imagen de portada. Gráfico surreal y fantasioso diseñado por kellepics disponible en needpix.

Jaimes, Freddy. Pseudociencias: Una manifestación del pensamiento errado. Instituto de Extrapolítica y Transhumanismo. 2020. DOI: 10.5281/zenodo.4058902

(C) Sociedad Secular Humanista del Perú (SSH).

Fondo Editorial de la Sociedad Secular Humanista del Perú.

Director Editorial: Víctor García-Belaunde Velarde.

Publicaciones del Instituto de Extrapolítica y Transhumanismo (IET) de la SSH.

Correo: extrapolítica@ssh.org.pe

Esta obra está bajo licencia internacional Creative Commons 4.0.
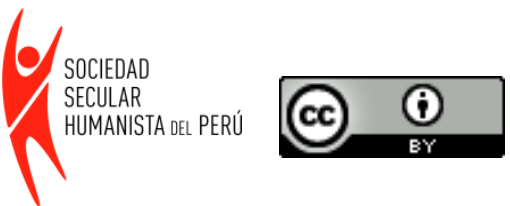


\section{Introducción}

La pseudociencia suele ser identificada como una manifestación de la ignorancia científica o una inexactitud en conceptos científicos que proviene de una confusión (confundir el concepto de satélite con el de planeta, o el concepto de la energía en física con el concepto tradicional ajeno a esta ciencia); sin embargo, la pseudociencia no se limita a una información errada, sino que implica una forma de pensar el mundo y las relaciones propias con ese mundo. Este artículo se escribe desde la preocupación de intentar entender la pseudociencia como un fenómeno del pensamiento y la posibilidad de acceder a su comprensión.

\section{EXISTENCIA DE LAREALIDAD}

Iniciamos desde el principio, y este consiste en que la realidad existe y no se trata solamente de una mirada, una interpretación antojadiza o una mera construcción social, tampoco una deconstrucción (como ciertos académicos seguidores del posmodernismo insisten en defender).

La realidad existe independientemente de nuestros estados de ánimo, de nuestra percepción, de nuestros estilos de pensamiento, de nuestro conocimiento del mundo y de la coyuntura, y existirá (ya sea un volcán o un terremoto, por ejemplo) con o sin nuestra presencia. Así pues, ella se configura como el conjunto de hechos físicos a los que accedemos por medio de nuestro aparato cognitivo, emocional, etc. La capacidad de conocerla se evidencia como un logro evolutivo, que también es parte de ella. Mas no solo nos valemos de los medios naturales, sino que también la tecnología nos ha permitido acceder a conocimientos más precisos a los que difícil o imposiblemente habríamos llegado sin su auxilio.

Mediante el conocimiento de lo que nos rodea podemos transformar la realidad y a nosotros mismos. Así, negarla implica negar la racionalidad, la posibilidad de certidumb re y, por tanto, la negación de la evidencia, que es la que nos ha llevado desde las cavernas al progreso de la humanidad. En otras palabras, negar la realidad es peligroso.

\section{COVARIACIÓN Y REALIDAD}

Una vez que se ha obtenido datos de la realidad, esta es pasible de ser analizada para inferir conocimientos, extrapolarlos y actuar conforme a ellos. Una de las formas de conseguir esto es a través de la identificación de causas y efectos.

La covariación es un principio que rige las relaciones causales. Consiste en un método lógico para reconocer que un fenómeno determinado es causado por otro: si la causa está presente cuando está presente el efecto y si está ausente cuando está ausente el efecto. Con la 
combinación de ausencias y presencias de ambos factores, se puede graficar una matriz de contingencia de cuatro celdas:

FACTOR A

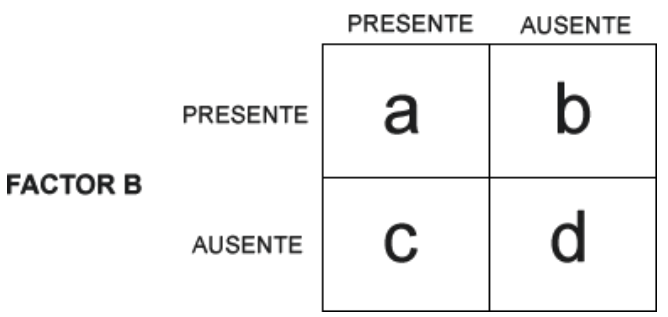

(Vásquez, C. 1985)

Para que una relación causal sea necesaria, debe considerarse los datos de las cuatro celdas, y de ellas solo deben ser verdaderas a y $d$.

Esta matriz es la base de un pensamiento que racionalmente identifique causas con efectos; sin embargo, cuando se trata de errado (falacias y sesgos cognitivos) se evidencia alguna falla en la matriz, ya sea por ausencia parcial de datos o por la interpretación errónea de las relaciones entre sus elementos.

\section{PENSAMIENTO ERRADO (PE)}

Consiste en la utilización de falacias y sesgos cognitivos en el pensamiento que suelen afectar las decisiones y juicios con el afán validar argumentativamente alguna pseudociencia. El presente trabajo rescata las definiciones de la filósofa española Montserrat Bordes Solanas, quien define falacia como: "un argumento no razonable o racionalmente no convincente, es decir, aunque puede ser válido, contiene un error inferencial por violar uno o más criteri os de buena argumentación." (p. 137) y sesgo cognitivo como: "una desviación sistemática de un criterio normativo que afecta al pensamiento causando errores de juicio". (p. 132).

El pensamiento errado es un patrón sistemático de desviación de la racionalidad y de los presupuestos científicos en el juicio en la medida que sea útil para mantener la consistencia argumentativa de uno o varios presupuestos pseudocientíficos. Esto incluye la selección intencionada o involuntaria de datos y publicaciones de múltiples fuentes que sirvan para justificar las creencias pseudocientíficas en cuestión (ej.: data mining). Es una manera de interpretar la realidad parcializada donde los individuos crean su propia justificación a partir de un juicio inexacto o una interpretación ilógica e irracional.

Con relación a los sesgos cognitivos, el psicólogo R. F. Pohl (2016) aporta una interesante precisión sobre su caracterización. En principio, afirma que en todos ellos se confirma una desviación significativa de la realidad, ocurren sistemática e involuntariamente (aunque el sujeto pueda percatarse de ellos, lo hace demasiado tarde), por lo que es difícil o imposible de evitar, y se sustenta en prejuicios (ideas, concepciones y opiniones previas) sin tomar en cuenta los datos que se encuentran en la realidad. 
Hay distintos tipos de $\mathrm{PE}$, sin embargo, a manera de ejemplo ahora solo se nombrará y definirá someramente quince de ellos, los más conocidos:

1. Falacia ad hominem: Se ataca a la persona en vez del argumento y así se evade el deber de justificar el argumento propio.

2. Falacia ad ignorantiam: Se apoya en la incapacidad de responder por parte del adversario, de manera que se asume que todo lo que se ha demostrado debe ser cierto.

3. Falacia ad populum: Se toma como prueba de la veracidad de un argumento a la opinión de la mayoría.

4. Falacia ad verecundiam: Se apela a una autoridad para defender la verdad o certeza de un argumento.

5. Falacia de pendiente resbaladiza: Se sugiere que un evento $X$ iniciará una cadena de acontecimientos y se apela a consecuencias remotas y desagradables que podría generar dicho evento.

6. Falacia naturalista: Se tiende a creer que algo es bueno esencialmente porque es "natural" o mal o porque es "antinatural" o "artificial".

7. Falacia petitio principii: Se utiliza la conclusión que necesita ser probada en alguna de las premisas.

8. Falacia post hoc, ergo propter hoc: Se tiende a asumir que hay relación entre dos variables, aunque no haya datos que lo confirmen.

9. Falacia del costo hundido: Se tiende a ocupar mucho tiempo y recursos para salvar proyectos que generan pérdidas en vez de apostar por otros nuevos.

10. Sesgo de confirmación: Se tiende a buscar y recordar aquello que se espera encontrar y rechazar aquello que lo contradice

11. Sesgo de efecto Dunning-Kruger: Se tiende sistemáticamente a pensar que se sabe más de lo que realmente sabe y considerarse más inteligente de lo que realmente se es. Suele darse en personas con escaso nivel intelectual y cultural.

12. Sesgo de efecto halo: Se tiende a aceptar o rechazar a una persona con apenas conocerla, bajo la asunción que solo unos minutos son suficientes para hacerlo.

13. Sesgo de efecto marco: Se tiende a ofrecer una respuesta o una elección en particular en función de cómo es la manera en la que se le presenta la información o en la forma en la que se realiza la pregunta, es decir, de la manera en la que este esté planteado, siendo esta forma el "marco" de la cuestión.

14. Sesgo de insensibilidad al tamaño de la muestra: Se espera que las muestras, independientemente de su tamaño, sean muy representativas de la población.

15. Sesgo de retrospección: Se tiende a que, cuando sucede algo que no se ha previsto, inmediatamente se ajusta la propia visión del mundo de manera que se logre el autoconvencimiento de que el fenómeno ya se había previsto. 
Referencias Bibliográficas

Bordes, M. (2017). Las trampas de Circe: falacias lógicas y argumentación informal. Madrid: Cátedra.

Bunge, M. (1985). Pseudociencia e ideología. Madrid: Alianza Editorial.

Dimara, E., Franconeri, S., Plaisant, C., Bezerianos, A. and Dragicevic, P. (2015) A Task-based Taxonomy of Cognitive Biases for Information Visualization. Journal of latex class files, Vol. 14, No. 8. 